\title{
Finite Element Analysis of Ti5553 Alloy during Equal Channel Angular Extrusion
}

\author{
Cai-Yun $\mathrm{MA}^{\mathrm{a}}$, Zhen-Hua $\mathrm{LI}^{\mathrm{b}}$ * and Cong-Rong ZHU ${ }^{\mathrm{c}}$ \\ School of Ship and Ocean Engineering, Zhejiang Ocean University, Zhoushan 316022, Zhejiang, \\ China \\ amacy1990@126.com, 'blizh760905@126.com, 'zhucr1108@126.com \\ *Zhen-Hua LI
}

Keywords: Ti5553 alloy; Equal channel angular extrusion (ECAE); Finite element analysis

\begin{abstract}
As different friction coefficients, extrusion speeds and extrusion temperatures have an effect on equal channel angular extrusion process of Ti5553 alloy under non-isothermal condition, 3D model had been set up to simulate the high temperature deformation behavior and particle tracking method was given to analyze the equivalent strain of Ti5553 alloy under that environment. The study shows that the maximum equivalent strain reaches 1.2 and occurs at the inside corner of the fan-shaped area. Moreover, when the friction coefficient more than 0 , the equivalent strain occurs in advance, the stress of the specimen at the entrance and exit increase and the stress distribution at the corner of the fan-shaped area is more unevenly. When the extrusion speed is $25 \mathrm{~mm} \cdot \mathrm{s}^{-1}$, the time of the specimen generates the same equivalent strain is shorter, the stress value of the specimen decreases, and the stress distribution of the specimen is more evenly.
\end{abstract}

\section{Introduction}

Ti5553 is a new near- $\beta$ titanium alloy [1] that exhibits excellent harden ability, a wide range of process ability, lower susceptibility to segregation, excellent strength, and higher fracture toughness and so on. However, the match of the strength and toughness of the existing Ti5553 alloy can't meet well with the requirements of aviation, which limit the application of high-strength Ti5553 alloys to some extent. Wang Hua et al:[2], found that the comprehensive performances of Ti5553 alloy, such as the strength, the ductility and the fracture toughness, are improved and achieve a good match by grain refinement which can be obtained by reasonable thermal processing methods.

Equal channel angular extrusion(ECAE) is a severe plastic deformation method and can obtain ultra-fine grains, which is proposed by Segal [3].This method has been successfully applied to TiAl [4] intermetallic compound, TiNi-based alloys [5], and so on, which can obtain small micron crystalline alloys which had excellent mechanical properties, physical properties, chemical properties.

At present, the research on Ti5553 alloy processed by ECAE has not been further found. In this paper, three-dimensional deformation process of Ti5553 alloy during high temperature ECAE is simulated by thermoplastic coupled finite element analysis (FEA) based on ABAQUS software, and the influence of friction coefficient, extrusion speed and extrusion temperature during ECAE are studied.

\section{ECAE Numerical Model and Finite Element Analysis}

The size of cross section of extrusion channel is designed as $10 \mathrm{~mm} \times 10 \mathrm{~mm}$, the length of the inlet channel is $125 \mathrm{~mm}$, the length of the outlet channel is $115 \mathrm{~mm}$, both the angular of inter corner arc $\Phi$ and outer corner arc $\psi$ are equal to $90^{\circ}$, as shown in Fig.1(a). The size of specimen is $10 \mathrm{~mm} \times 10$ $\mathrm{mm} \times 90 \mathrm{~mm}$. To simplify analysis process, ECAE die and plunger are set to be rigid body[6]. The temperature of the die is $773 \mathrm{~K}$, the temperature of the specimen is set as $923 \mathrm{~K}, 1023 \mathrm{~K}, 1123 \mathrm{~K}$ and $1223 \mathrm{~K}$, and the temperature of the environment is $293 \mathrm{~K}$. The material of the specimen is Ti5553 alloy and its chemical composition is $5 \% \mathrm{Al}, 5 \% \mathrm{Mo}, 5 \% \mathrm{~V}, 3 \% \mathrm{Cr}, 0.65 \% \mathrm{Zr}$ and the other is $\mathrm{Ti}$. 
The speed of the plunger is set as $6 \mathrm{~mm} \cdot \mathrm{s}^{-1}$ and $25 \mathrm{~mm} \cdot \mathrm{s}^{-1}$. The friction coefficient of $0,0.05$ and 0.1 was selected in the study.

The particle tracking method of ABAQUS is used to analyze the variation of the equivalent strain curve about the three feature points at various friction coefficients, extrusion speeds and extrusion temperatures. The three feature points P1、P2 and P3 are located at 1/2 plane of the specimen, which is shown in Fig.1(b).
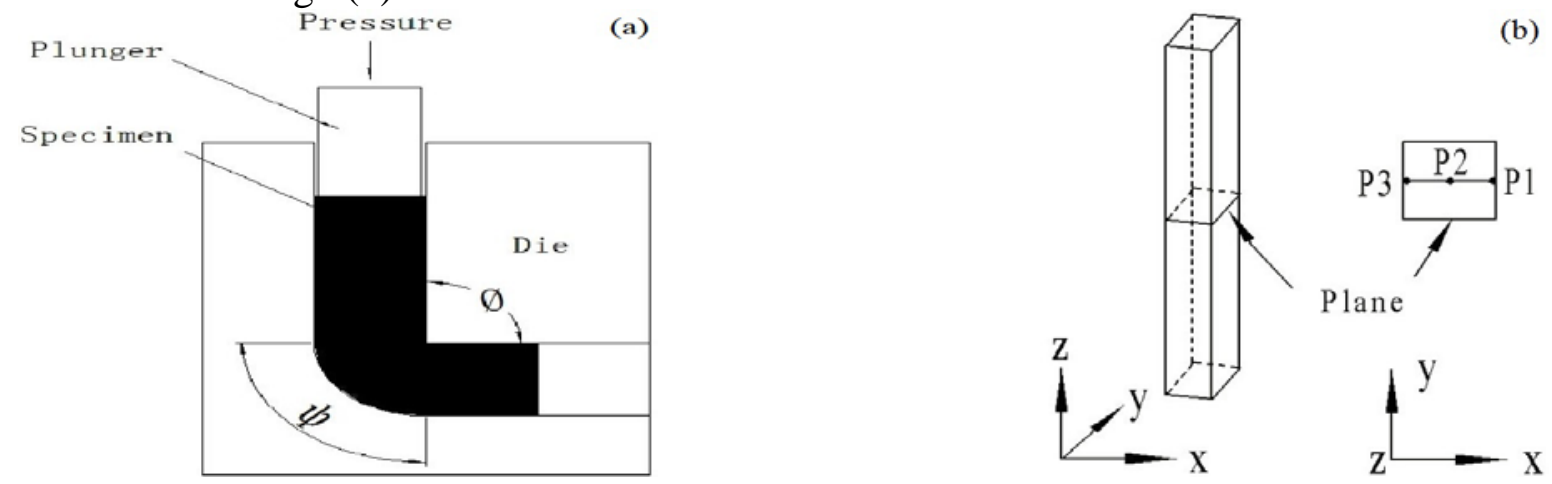

Fig. 1 Schematic illustration of (a) the ECAE facility and (b) the selected tracking points of the specimen.

\section{Results and Discussion}

\section{The Influence of Friction Coefficient During ECAE}

\section{The Distribution of Equivalent Strain under Different Friction Coefficients}

According to Fig. 2, we can see that before these points entered the corner, no strain is observed, but when these points passed through the corner, the equivalent strains of all of these points rapidly increase to the maximum, which is similar to the study of Kim[7]. Besides, the maximum equivalent strain occurs at the inside corner of the fan-shaped area (P1). Meanwhile, it could be found that under different friction coefficients, the maximum equivalent strain value of P1 are greater than 1 . However, according to the theoretical equation,

$$
\varepsilon_{\mathrm{N}}=\frac{N}{\sqrt{3}}\left[2 \cot \left(\frac{\phi}{2}+\frac{\psi}{2}\right)+\psi \operatorname{cosec}\left(\frac{\phi}{2}+\frac{\psi}{2}\right)\right]
$$

which is provided by Iwahashi [8], the value is equal to 0.97. It means that not only shear happened in the corner, other influences should exist. The maximum equivalent strain values of P2 and P3 are less than 1, which is lower than the theoretical value.

Another phenomenon should be given attention to is that with the increase of the friction coefficient, the equivalent strain occurs in advance and the difference between the maximum equivalent strain value of P1 and P2 became smaller. The reason is that the friction resistance increase along with the increase of the friction coefficient, which will cause the flow rate of the specimen surface to decrease. At the same time, immense heat is produced, which accelerated the motion of molecular and the generation of the plastic deformation at the corner of the specimen. 


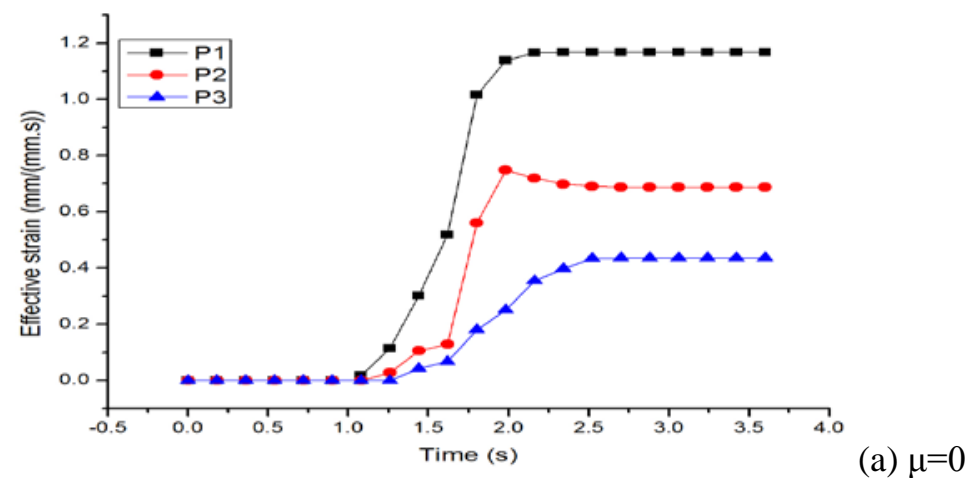

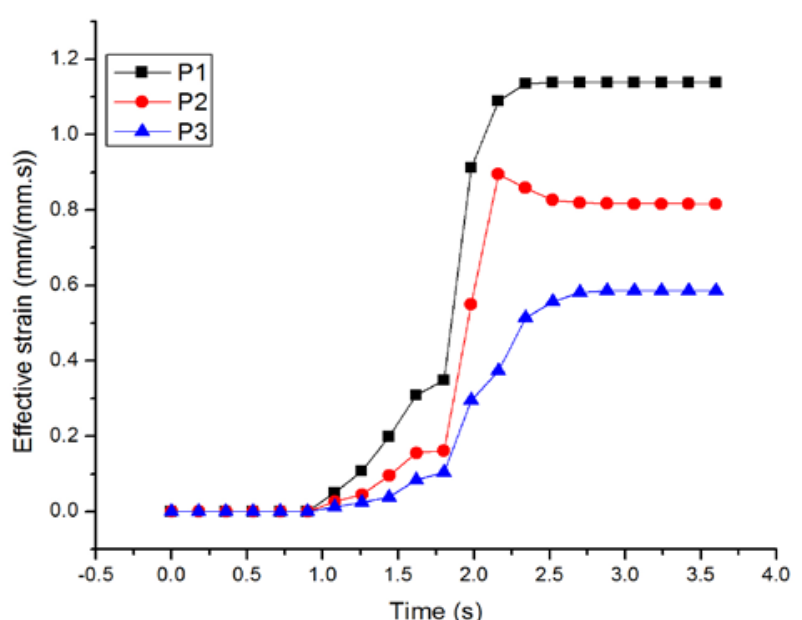

(b) $\mu=0.05$

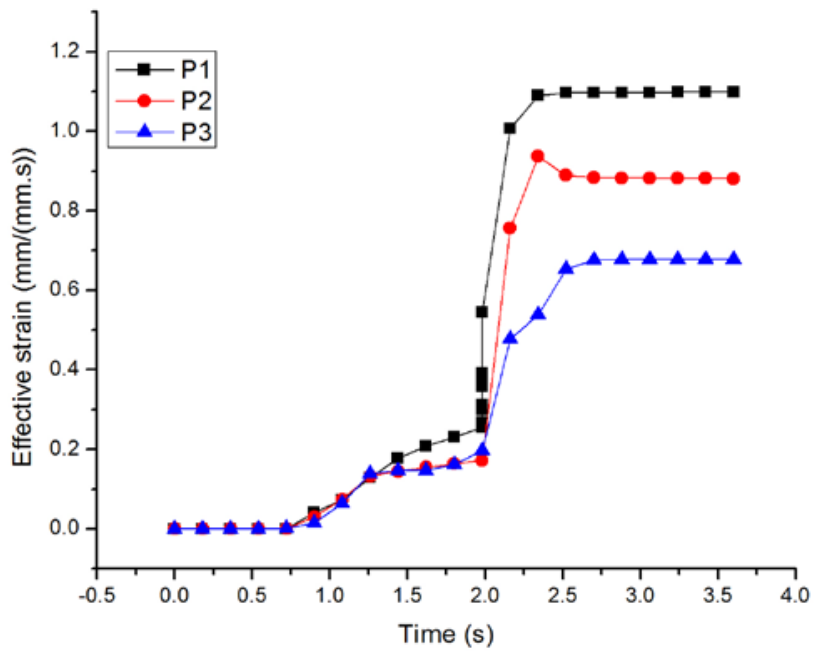

(c) $\mu=0.1$

Fig. 2 The equivalent strain curve under different friction coefficients. $\left(T=1123 \mathrm{~K}, \mathrm{v}=25 \mathrm{~mm} \cdot \mathrm{s}^{-1}\right)$.

\section{The Distribution of Stress under Different Friction Coefficients}

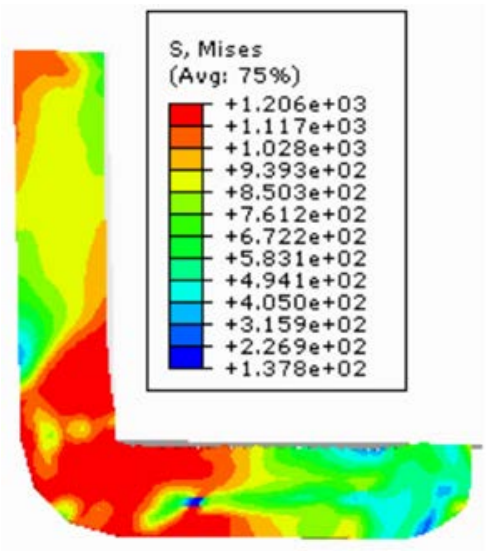

(a) $\mu=0$

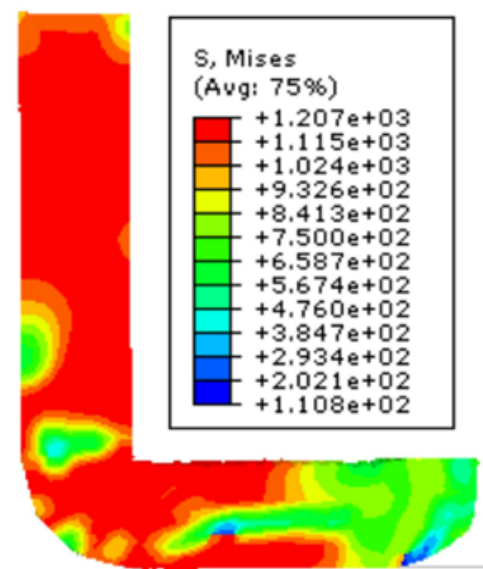

(b) $\mu=0.05$

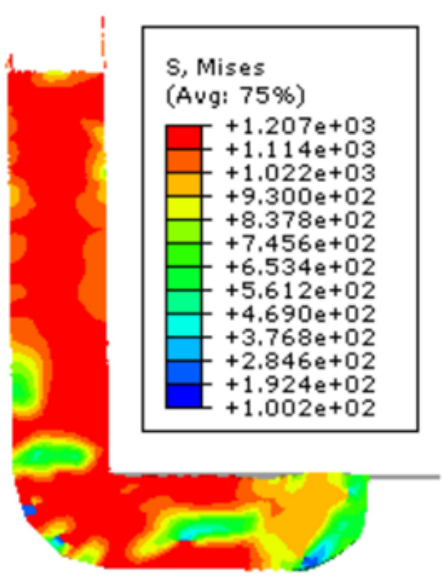

(c) $\mu=0.1$

Fig. 3 Stress distribution under different friction coefficients. $\left(T=1123 \mathrm{~K}, \mathrm{v}=25 \mathrm{~mm} \cdot \mathrm{s}^{-1}\right)$.

According to Fig. 3, we can see that the stress always exists during the whole ECAE process. With the increase of friction coefficient, the stress of the specimen at the entrance and exit increase and the stress distribution of the specimen at the corner of the fan-shaped area is more unevenly. The reason is that the friction resistance to the specimen increase along with the increase of friction coefficient, the friction resistance will cause the flow behavior of the unevenly distribution of the specimen along the radial. That is the flow velocity of the specimen at the axis is faster than it close to the cavity at the side wall. The difference of the flow rate of the specimen between the axis and close to the cavity at the side wall will increase and the trend of the uneven deformation flow of the specimen will significant increase along with the increase of the friction resistance, which is in 
accordance with LI F. [9] reported.

\section{The Influence of Extrusion Speed During ECAE}

\section{The Distribution of Equivalent Strain under Different Extrusion Speeds}

According to Fig. 4, we can see that there are little difference among general trend of the equivalent strain at P1 and P3 under the extrusion speed of $6 \mathrm{~mm} \cdot \mathrm{s}^{-1}$ and $25 \mathrm{~mm} \cdot \mathrm{s}^{-1}$, but the equivalent strain value of $\mathrm{P} 2$ reached to a peak value, then rapidly dropped down under the extrusion speed of $25 \mathrm{~mm} \cdot \mathrm{s}^{-1}$. This trend is consistent with the discontinuous yielding as Warchomicka reported [10]. It is considered that the main reason for this phenomenon is that greater deformation energy of the specimen is stored under the extrusion speed of $25 \mathrm{~mm} \cdot \mathrm{s}^{-1}$, which will cause the strain rate of the specimen at the corner added to 0.83. Excessive strain rate will lead to a sharp accumulation of dislocations and the stress concentration, which can't be released and will suppress the nucleation of the dynamic recrystallization, and ultimately cause the equivalent strain of the specimen increase to maximum and then has a decline at the corner.

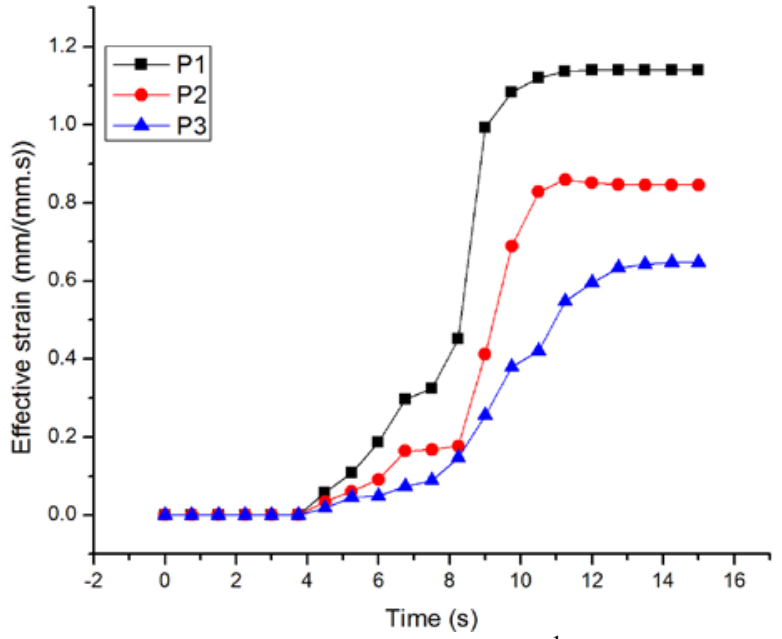

(a) $\mathrm{v}=6 \mathrm{~mm} \cdot \mathrm{s}^{-1}$

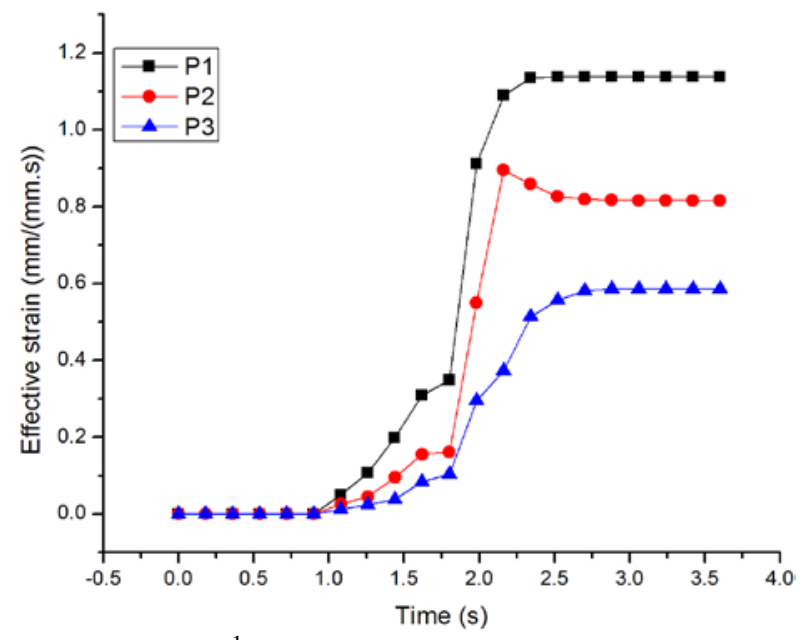

(b) $v=25 \mathrm{~mm} \cdot \mathrm{s}^{-1}$

Fig. 4 The equivalent strain curve under different extrusion speeds. ( $T=1123 \mathrm{~K}, \mu=0.05$ ).

\section{The Distribution of Stress under Different Extrusion Speeds}

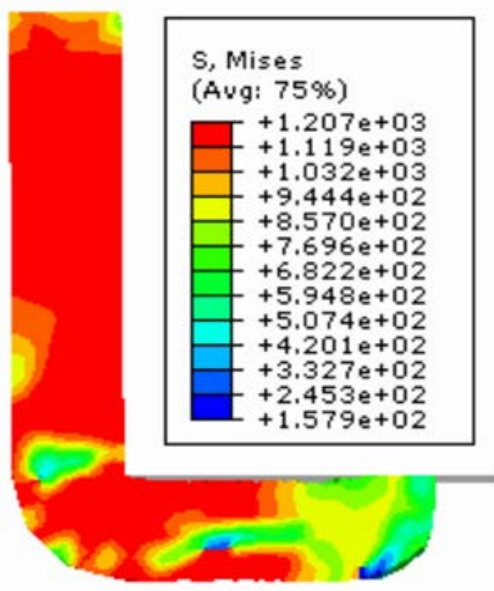

(a) $\mathrm{v}=6 \mathrm{~mm} \cdot \mathrm{s}^{-1}$

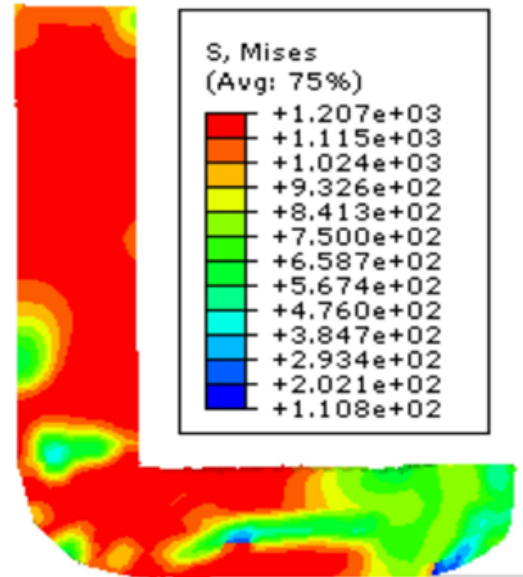

(b) $\mathrm{v}=25 \mathrm{~mm} \cdot \mathrm{s}^{-1}$

Fig. 5 Stress distribution under different extrusion speeds. ( $\mathrm{T}=1123 \mathrm{~K}, \mu=0.05)$.

According to Fig. 5, we can see that at the outlet, the stress distribution of the specimen is more evenly under the extrusion speed of $25 \mathrm{~mm} \cdot \mathrm{s}^{-1}$, which indicate that the deformation of the specimen is more evenly under the extrusion speed of $25 \mathrm{~mm} \cdot \mathrm{s}^{-1}$. This phenomenon attributes to the higher energy and severe shear deformation at the corner when the extrusion speed rise, which will lead 
the increasing tendency of the unstable high-energy state to the stable low-energy state.

The Influence of Extrusion Temperature during ECAE

The Distribution of Equivalent Strain under Different Extrusion Temperatures

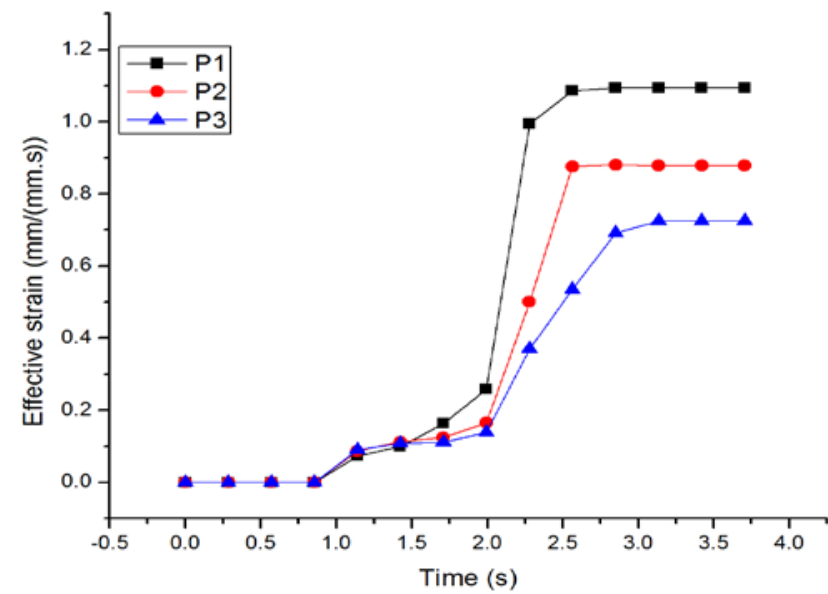

(a) $\mathrm{T}=923 \mathrm{~K}$

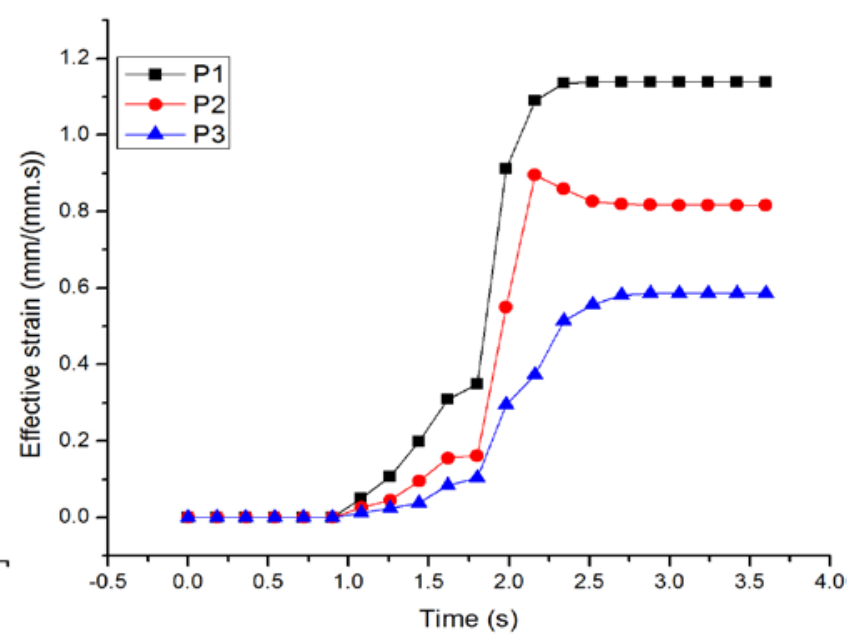

(b) $\mathrm{T}=1023 \mathrm{~K}$

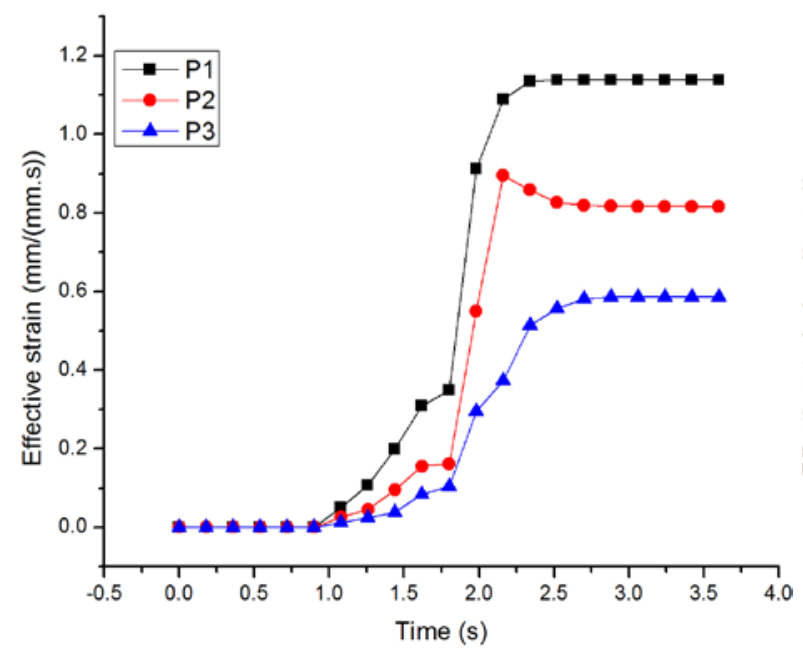

(c) $\mathrm{T}=1123 \mathrm{~K}$

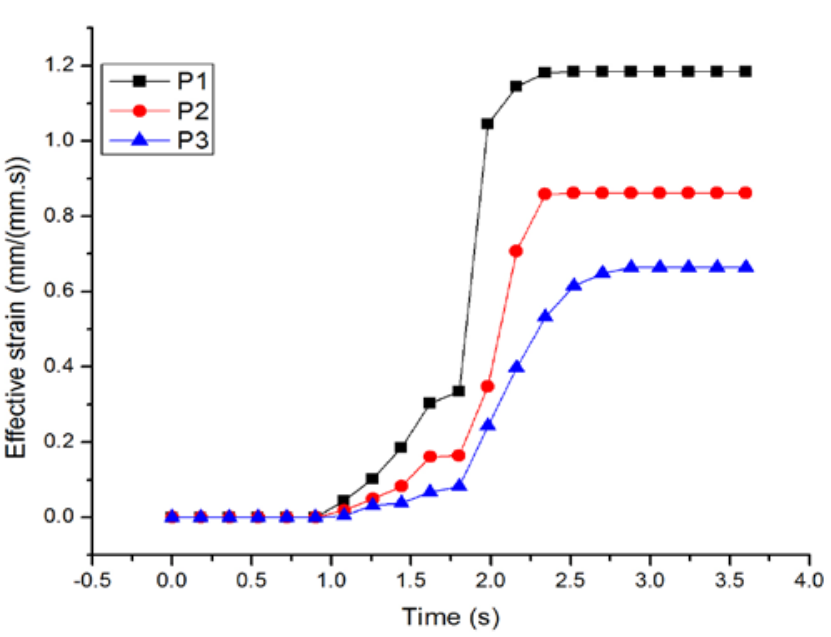

(d) $\mathrm{T}=1223 \mathrm{~K}$

Fig. 6 The equivalent strain curve under different extrusion temperatures. $(v=25 \mathrm{~mm} \cdot \mathrm{s}-1, \mu=0.05)$.

As Fig. 6 shows, under different preheat temperature, before the selected tracking points pass through the corner, the equivalent strain values of them have almost little change. When the selected tracking points pass through the corner, the equivalent strain curve of P1 and P3 have little change, while the equivalent strain curve of P2 has a significant difference. Under the preheat temperature of $1023 \mathrm{~K}$ and $1123 \mathrm{~K}$, the equivalent strain value of P2 rise to the maximum and then decrease. That is because the recrystallization temperature of titanium element is in the range of $875 \mathrm{~K} \sim 961 \mathrm{~K}$, while other alloy elements in Ti5553 alloy, has higher melting points, such as Mo, V, $\mathrm{Cr}$ and $\mathrm{Zr}$, distributing at the grain boundaries and retarding the migration of grain boundaries, which cause the recrystallization temperature to increase. Thus it can be assumed that when the extrusion temperature is $923 \mathrm{~K}$, the recrystallization process is seriously hindered. When the extrusion temperature are $1023 \mathrm{~K}$ and $1123 \mathrm{~K}$, these temperature is higher than the recrystallization temperature of the high-melting alloy elements $\mathrm{V}, \mathrm{Cr}, \mathrm{Zr}$, which make the recrystallization process is little hindered. Moreover, the equivalent strain curve has a decline tendency because of high extrusion speed after the specimen passes through the corner. When the extrusion temperature is 
$1223 \mathrm{~K}$, the temperature has exceed the recrystallization temperature of all the high-melting alloy elements in Ti5553 alloy, which make the resistance which retarded the migration of grain boundaries disappear, and a few special boundaries quickly migrating after the specimen produce a large deformation at the corner, which cause a few grains to grow up and secondary recrystallized structure form which is driven by the grain boundary energy.

\section{The Distribution of Stress under Different Extrusion Temperatures}

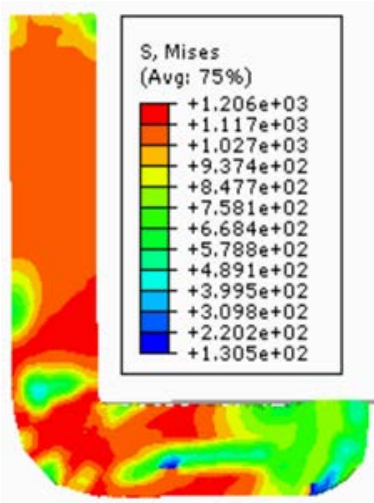

(a) $\mathrm{T}=923 \mathrm{~K}$

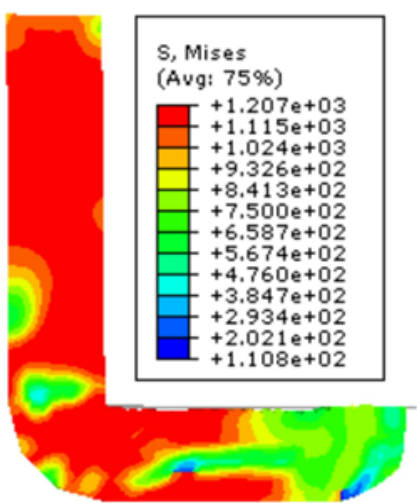

(b) $\mathrm{T}=1023 \mathrm{~K}$

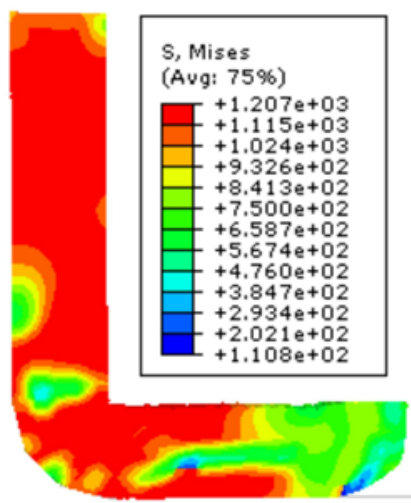

(d) $\mathrm{T}=1223 \mathrm{~K}$

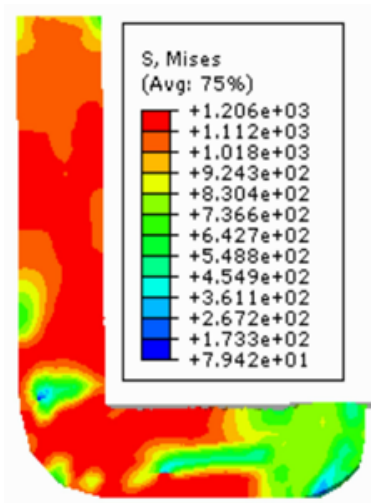

(c) $\mathrm{T}=1123 \mathrm{~K}$

Fig. 7 Stress distribution under different extrusion temperatures. ( $v=25 \mathrm{~mm} \cdot \mathrm{s}-1, \mu=0.05)$.

As Fig. 7 shows, when the preheat temperature are $1023 \mathrm{~K}$ and $1123 \mathrm{~K}$, the distribution of the stress of the specimen are more evenly than that under the preheat temperature of $923 \mathrm{~K}$ and $1223 \mathrm{~K}$. This phenomenon is attribute to higher extrusion temperature, which lead to the deformation resistance and extrusion force of the specimen decrease and the extrusion of the specimen become more easily. But when the preheat temperature is $1223 \mathrm{~K}$, the stress decrease and the distribution of it unevenly. These can be ascribed to the resistance which retard the migration of grain boundaries disappears and the phenomenon of grain growth generate in such circumstances, which lead to the energy of the grain boundary surface decrease.

\section{Conclusions}

1) Before entering the corner, there exists no strain, but when these points pass through the corner, the equivalent strain of all points rapidly increase to the maximum. Besides, the maximum equivalent strain value occurs at $\mathrm{P} 1$, and reach to 1.2 .

2) With the increase of friction coefficient, the occurrence of the equivalent strain is in advance, the stress of the specimen at the entrance and exit increase and the stress distribution of the specimen at the corner of the fan-shaped area is more unevenly. With the increase of extrusion speed, the stress distribution of the specimen is more evenly under the extrusion speed of $25 \mathrm{~mm} \bullet \mathrm{s}^{-1}$.

3) The equivalent strain value of $\mathrm{P} 2$ is greater impacted by the preheat temperature and the extrusion speed.

\section{Acknowledgements}

The authors would like to thank the financial support of National Natural Science Funds for Youth of China (No. 51205359), State Key Laboratory of Tribology of Tsinghua University (SKLTKF13A06) and the Science and Technology Department of Zhejiang province(2014C33086).

\section{References}

[1] Zhao D.H., Wang L., Zhi M.S., 2013. Microstructures and mechanical properties of near-beta Ti-5553 alloy under high strain rate loading. Chinese Journal of Stereology and Image Analysis. 18(4), 356- 360. 
[2] Wang H., Dai G.H., 2014. A Thermal Processing Method of Improving Comprehensive Performance of Ti5553 Alloy. Titanium Industry Progress. 31(1), 32-34.

[3] Hu H. J., 2012. Simulations of isothermal ECAE for magnesium alloy using FEM software and experimental validations. Journal of Manufacturing Processes. 14, 181-187.

[4] Asier Ugarte, Rachid M Saoubi, Ainhara Garay, et al. 2012. Machining behaviour of Ti-6Al-4V and Ti-5553 alloys in interrupted cutting with PVD coated cemented carbide. Procedia CIRP. 1, 202-207.

[5] Song J., Wang L. M., Sun X. G., et al. 2012. Effects of second phases on mechanical properties and martensitic transformations of ECAPed TiNi and Ti-Mo based shape memory alloys. Trans. Nonferrous Met. Soc. China. 22, 1839-1848.

[6] Si J.Y., Wu X.L., Xia K.N., et al. 2014. Equal Channel Angular Extrusion of TB2 Alloy under Different Die Designs by Finite Element Method. Rare Metal Mater. and Eng. 43(7), 1577-1581.

[7] Kim J. K., Kim W. J., 2006. Analysis of Deformation behavior in 3D During Equal Channel Angular Extrusion. J Mater Process Technol. 176(1-3), 260-267.

[8] Iwahashi Y., 1996. Principle of Equal-channel Angular Pressing for the Processing of Ultra-fine Grained Materials. Scripta Materialia. 35(2), 143-146.

[9] LI F., LIU X. J., YUAN S. J., 2008. Effect of friction condition on flow behavior of aluminum alloys during extrusion. The Chinese Journal of Nonferrous Metals.18(11), 2014-2019.

[10] Warchomicka F., Poletti C., Stockinger M., 2011. Study of the hot deformation behaviour in Ti-5Al-5Mo-5V-3Cr-1Zr. Mater. Sci. Eng. A. 528(28), 8277-8285. 